\title{
Impact of 'Self-Portrait' Creation and Discussion Workshop on Body Image of Indian Female Teenagers
}

\author{
Muskaan Mittal ${ }^{1}$ and Kah Ying Choo ${ }^{2}$ \\ ${ }^{1}$ The Shri Ram School, Aravali, India \\ ${ }^{2}$ Awakening Minds, Singapore
}

\section{$\underline{\text { ABSTRACT }}$}

It is widely believed that body image issues affect the emotional and psychological well-being of adolescents to a great extent. In the face of deeply entrenched normative beauty standards, teenagers' struggles with body image issues can be extremely damaging. This study assessed the impact of an interactive online workshop involving the creation and sharing of 'self-portraits' on the body image of urban Indian female teenagers, aged 13 to 16. Data were gathered in the form of photographs of the participants' artworks, their comments about each other's artworks, as well as responses to a short open-ended questionnaire. This study revealed that the workshop was helpful in encouraging the participants to acknowledge their sense of isolation in dealing with body image issues. Furthermore, they greatly benefitted from a platform that gave them the opportunity to express their feelings and understand that they were not alone in their struggles. This empowered them to move towards self-acceptance and a desire to redefine unrealistic beauty standards. Ultimately, this study validated the value of the workshop in helping teenagers deal with their body image issues through creative means. In the future, regular sessions should be held to address teenagers' body image issues through creative means and provide them with support in facing the pressures of prevalent beauty standards. As parents could inadvertently be contributing to their children's body image issues, this study also proposed efforts to educate parents on the promotion of body positivity in their children.

"Wait... Do you have a moustache?"

Little did I know that this seemingly innocuous question would cause me, a 12-year-old girl at the time, to develop an intense dislike for my upper lip hair. I would literally stare at it in the mirror for hours on end, wishing it were never there. At 13, when I hit puberty, my preoccupation with my body image shifted to my widening hips and thighs. It was only partially assuaged by a comment that "boys find large hips attractive", though my large thighs continued to cause me grief. All around me, friends were dieting and showing off their latest exercises for losing weight. Amidst this relentless pressure to achieve the "slim ideal", it seemed impossible for me to love my body the way it was at any given time.

\section{Introduction}

My experiences, personal as they may sound, are representative of the widespread teenage susceptibility to body image issues. This is due to dramatic bodily "changes in weight, height, body shape, body composition, as well as primary and secondary sex characteristics" (Voelker et al., 2015, p. 150) that occur during this phase. The concomitant increase in the exposure to cultural ideals of beauty promoted in the media further aggravates their negative perceptions of those pubertal changes that move their physical appearance in a direction opposite to that of the "thin ideal" (Voelker et al., 2015).

Apart from the media, adolescents also have to cope with pressure from the people around them. In particular, Webb and Zimmer-Gembeck (2013) found that friends and peers strongly influence adolescent body dissatisfaction 
in different ways. Conversations that reinforce the adherence to appearance ideals, appearance-centered teasing, and friends' dieting behaviors can lead to the internalization of pressure for one to be thin (Voelker et al., 2015).

Within the context of the urban Indian society, which is the setting of this research study, the young 'Westernized' generation in India can be considered to be experiencing pressure to meet a new ideal of beauty entirely - a Western-influenced modification of the Indians' traditional definition of attractiveness. This has led to an amalgamation that has the potential to be both physically and emotionally damaging for Indian women (Gelles, 2011) by establishing unrealistic expectations that may be even be irreconcilable.

Based on the traditional conception of Indian beauty, "The ideal Indian woman is fair or medium-complexioned, has a narrow waist but wider hips and breasts, and has large eyes, full red lips, and long black hair that is either straight or wavy" (Gelles, 2011, p. 11). Essentially, the traditional ideal Indian beauty standard does celebrate "curvy hourglass figures and even the occasional hint of extra fat in the stomach area" (Gelles, 2011, p. 20). However, when combined with Western beauty standards that emphasize fair skin and slim figures (Gelles, 2011), this results in an even more constrained definition of beauty. Thus, the new ideal comes out to be a fair complexion, a slim body, characterized by a thin waist and no belly fat, but large breasts and wide hips. This portrait barely even resembles a real woman!

It is against this backdrop that society needs to take into account the grave impact of body image issues on vulnerable individuals who are driving themselves to attain an unrealizable ideal. More than just a superficial preoccupation with outward appearance, body image is a multidimensional dynamic concept that encompasses a person's perceptions, thoughts and feelings about his or her body, which can in turn and affect his/her psychological wellbeing, as well as how he/she acts towards his/her body (Grogan, 2008; Voelker et al., 2015).

As a result of my own struggles with body image issues, I have embarked on a mission to fight for body positivity by initiating 'Project Surfaces' - a movement to improve body image, boost self-esteem and encourage self-acceptance through expressive means. On the project's Instagram page, I have put up videos of my peers answering questions about their own experiences with body image and beauty standards (see Figure 1).

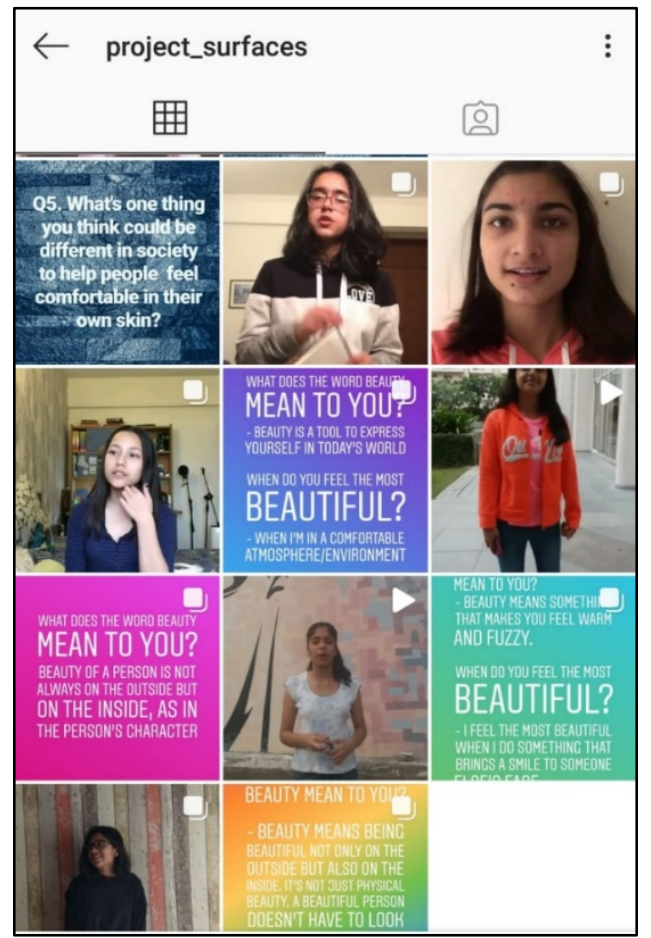

Figure 1. Screenshot of Peers Answering Questions from Instagram Page of 'Project Surfaces' 
In addition, I curated music, art, poems, and movie quotes on this Instagram account to create an online resource bank to promote body positivity (see Figure 2).
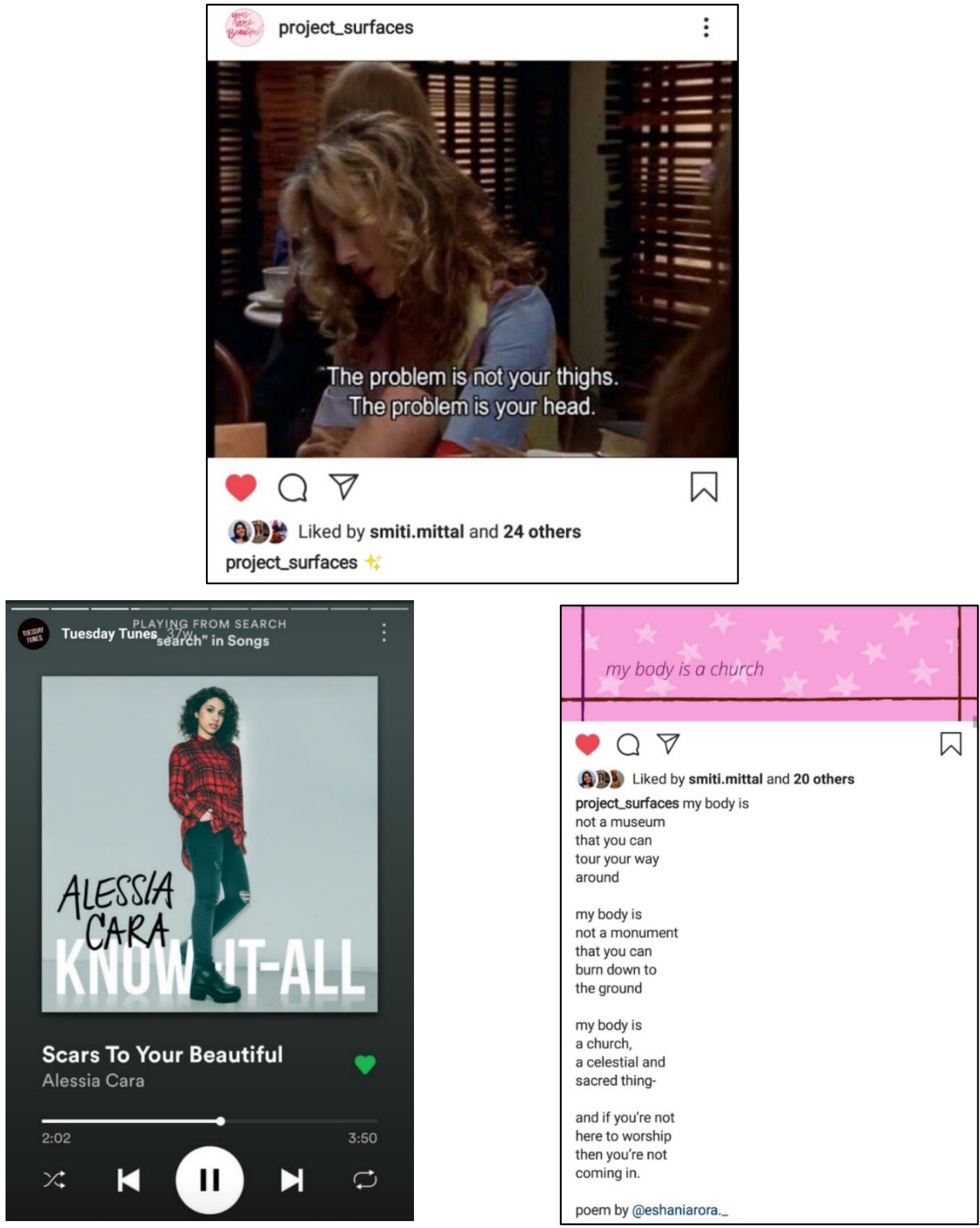

Figure 2. Screenshots of Online Resource Bank from Instagram Page of 'Project Surfaces' 


\section{Description of Research Study}

\section{Research Aim}

To further understand how creative and expressive means could be harnessed to improve body image, I developed an innovative interactive workshop that involves participants creating 'self-portraits' and talking about them in an anonymized online workshop setting. This process would then trigger an overall discussion among all participants on the topic of body image. The aim of this research study was to assess the impact of this workshop on the body image of Indian female teenagers, aged 13 to 16.

One of the primary objectives of the workshop was to offer participants the space to express their body image issues through the creative outlet of making 'self-portraits'. These 'self-portraits', be they drawings or paintings, could be as realistic or as abstract as they liked, thus allowing for individual self-expression. Furthermore, the participants had the opportunity to describe their artworks and discuss their self-image as it related to these artworks.

Research has shown that art therapy can be an effective way for dealing with psychological issues (Sanders, 2013). More specifically, Gaete (2010) addressed the significance of three dimensions of art therapy in exerting a healing effect on one's body image:

1. "sensory motor coordination dimension": physical act of drawing

2. "affect-emotional dimension": impact of making art on one's feelings; and

3. ownership of one's body and the art created

The healing effect of art on the body image takes place by allowing the individual to: 1) develop the self through playing and creativity; 2) recognize his/her unconscious conflict through the art-expression; and 3) internalize and integrate concepts of form, content, and meaning of body. Therefore, the entire process seeks to harness the creativity of the art-making process to allow for the unconscious integration of a healthy conception of one's body with one's inner self (Gaete, 2010).

\section{Research Approach}

As the research study was focused on the participants' experiences of the workshop and its impact on their body image issues, the Interpretative Phenomenological Analysis (IPA) approach was adopted. The IPA approach encompasses three key components: "phenomenology, hermeneutics, and idiography" (Pietkiewicz \& Smith, 2014, p. 8):

- Phenomenology: concerns how people perceive a specific experience, i.e., a phenomenon, from their perspectives (Pietkiewicz \& Smith, 2014).

- Hermeneutics: concerns the interpretations of these experiences by the researcher, which is why Smith and Osborn (2008) explained how IPA is often a double-layered interpretation process in which the researcher seeks to interpret the participants' perceptions of their experiences.

- Ideography: concerns a deep examination of the experiences of individual participants, which leads to the generation of larger themes that would constitute a composite picture of the phenomenon under investigation (Pietkiewicz \& Smith, 2014).

Within the context of this research study, the IPA approach would be highly illuminating in examining how the workshop can affect their body image. 


\section{Sampling}

Purposive sampling was used for this research study. Specifically, the research study was limited to Indian female teenagers (aged 13-19). The selection of each of these characteristics is deliberate. Even though body image issues affect almost all people at all ages, this research study is centered around the experiences of teenagers to account for the pubertal development issues that can make them extremely highly vulnerable to body negativity. Furthermore, being younger, they do possess the potential to transform their mindset and overcome their body image issues.

The limitation of the sample to Indian teenagers, rather than opening it to other ethnicities, is meant to further reinforce the originality of this research study due to the lack of qualitative studies directed towards understanding the extent to which prevalent beauty standards, stereotypes and norms of the Indian society have affected Indian teenagers. While it is important to acknowledge that Indian male teenagers also experience body image issues, the decision to involve only female teenagers was to optimize the sense of psychological safety among the participants due to the sensitivity of the topic.

In order to gather the desired sample, an invitation briefly describing the purpose and program of the research study was circulated on WhatsApp and Instagram (see Appendix A). Although the workshop was open to all Indian female teenagers (aged 13-19), interested candidates who ended up replying were all urban Indian female teenagers, aged 13-16.

Prior to the workshop, participants were sent detailed information and instructions about the workshop, reiterating the research aim, the research setting (described below), the program, as well as logistical details about the date, time, and duration of the session (see Appendix B). Once again, the concern was to ensure that the participants felt as secure as possible in participating in a challenging workshop that entailed exposing their vulnerabilities. Ultimately, seven people participated in the study.

\section{Description of the Research Setting}

The two workshop sessions took place on Zoom. In order to create a safe space for sharing, participants had their identities protected from one another through the disabling of their videos and the use of codenames. This anonymized the discussion that took place after making and sharing of the artworks. I alone knew the participants' real-life identities.

\section{Data Collection}

Of the two Zoom sessions conducted, one lasted an hour and 15 minutes, while the other lasted nearly two hours. The program for the workshop was as follows:

1. Participants were welcomed to and briefed on the workshop. Instructions and rules about the presentation and the discussion of the 'self-portraits' were reiterated. The participants were essentially told to be respectful and constructive in what they said to one another, as they should all be celebrated for their willingness to take part in a workshop on such a sensitive topic. They were also reminded to respect the confidentiality of the sharing. Finally, permission was sought and granted to videotape the session, solely for data analysis purposes.

2. Next, the participants were given 30 minutes to make their 'self-portraits' in any medium of their choice. Their artwork could be as realistic, abstract, fanciful, and partial as they liked. From the seven participants, 
a total of eight pieces of artwork was received: while one participant sent three images, one did not wish to share her image, and the rest sent one image each.

3. One by one, I showed pictures of the various 'self-portraits' to the rest of the group. As I showed the images, the participant who had made it got the chance to share about it for a few minutes to all the other participants. They could either unmute themselves and speak to the group or type their messages in the chat box to be read by all the participants online. Other participants then had the opportunity to respectfully comment on what the participant had said/drawn in the same manner.

4. Following this sharing about the individual images, a general discussion took place among the participants regarding the 'self-portraits', the sharing, and their experiences with body image.

5. At the end of the workshop, the participants were instructed to complete an online survey containing four open-ended questions about the impact of the workshop on their body image. Below are the questions and the rationale behind each of them. Together, they aimed to truly capture the thoughts, feelings, and voices of the participants:

- "How did drawing/painting a representation of how you think you look make you feel about your body?": This question sought to reveal the impact of creative expression on body image.

- "How did seeing other people's artwork and discussing the drawings/paintings with them make you feel about your body?": This question assessed the impact of seeing others' 'self-portraits' and subsequent discussion on body image.

- "Do you feel like you have come closer to shedding an irrational beauty standard from your mind today? Please elaborate on your response.": This question addressed the overall and broader effect of the entire workshop on the individual's body image.

- "If you want to add anything about the effects of this experience made you feel, or how it has affected you (e.g., any changes in mood, body positivity, self-esteem, self-awareness, etc.), please do so below.": This question provided the opportunity for the participants to bring up additional thoughts or feelings that might not have fitted into the answers to the previous questions.

Data collected from the workshops thus comprised the responses to the 'self-portraits' with their accompanying descriptions and comments, the discussions, as well as the online questionnaire.

\section{Data Analysis}

Thematic analysis was used to examine the qualitative data by following the step-by-step guidelines of Pietkiewicz and Smith's (2014) article, “A Practical Guide to Using Interpretative Phenomenological Analysis in Qualitative Research Psychology":

- Step 1: Immersing in the data by listening to the video recordings multiple times and transcribing relevant data, while making notes;

- $\quad$ Step 2: Re-reading the notes and studying the related data including the 'self-portraits' to convert them into emergent themes;

- Step 3: Forging relationships between the emergent themes in order to group them to form the final themes. 


\section{Findings}

\section{Theme 1: Illumination of Isolation in Individual Coping}

Through the various aspects of the workshop - the drawings, discussions and responses to the open-ended questions, the participants revealed an overwhelming feeling of isolation in their endeavors to cope with body image issues. For a start, it is evident that they were hyperconscious of normative beauty standards. This is shown in their comparisons of their own physical appearance with conventional beauty standards:

I don't think that I'm overweight. I just feel that I'm not skinny either. (Powerpuff Girl)

I'm not super overweight, I'm not super skinny, I'm just kind of there in the middle. (Pink Panther)

I just imagine had I had... a shorter nose, less acne and better skin, I might have looked and felt better about myself. (Sudoku)

All the participants were cognizant of the negative impacts of this quest to conform to beauty standards:

I feel that traditional beauty standards are wildly discriminatory and create negative body image issues. (Pink Panther)

Even the most beautiful person on this planet will only see flaws in their body. (July)

Yet unfortunately, they had internalized these normative expectations after years of exposure to judgements from the outside world:

From what I could make out of other people's opinions about themselves and their bodies, most of us believe being beautiful = being skinny. Even though I reject that belief forcefully, it still remains in my head. (Sudoku)

In fact, the deep-rooted nature of this internalization is captured vividly in both the artworks of July and Pink Panther artworks. The depictions of their faces and beings are bereft of the distinctive facial features. Instead, they have been wiped out by the 'voices' of society (see Figure 3)

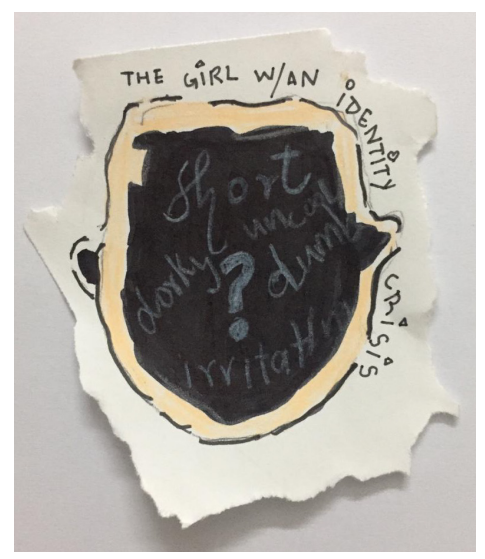

Figure 3. 'Self-Portrait' of July (1) 
July's description of her initial body-image in the form of the things people said about her: "...because I'm short... people just keep talking about the same things... People just call you names at school and it just [gets] to you."

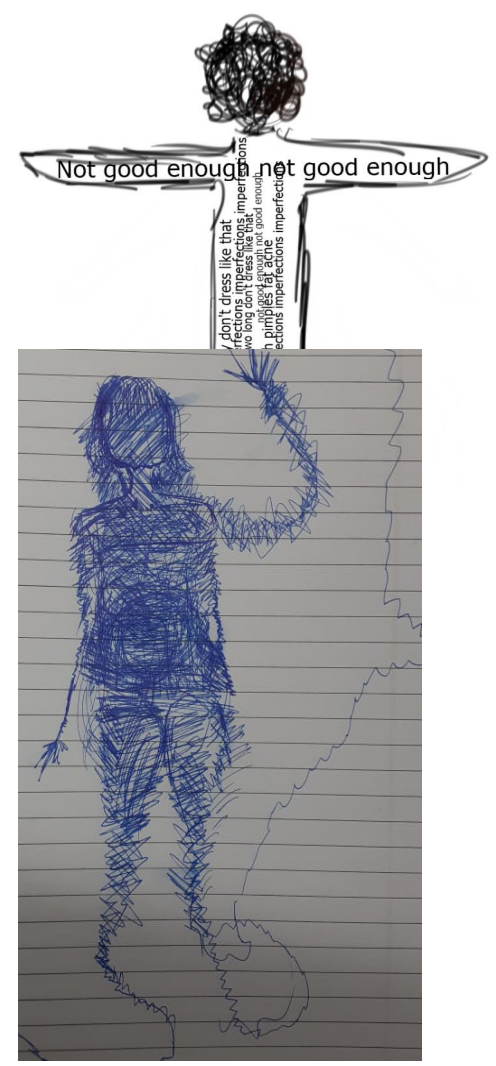

Figure 4. 'Self-Portrait' of Pink Panther

Pink Panther's description of her 'self-portrait' as being deeply influenced by external voices: "I just put in a bunch of different words that I think of when I look at myself in the mirror, and how I've heard other people talk about me. There's a lot of, mostly, unfortunately, negative stuff."

Pink Panther's depiction of herself, which almost resembles a 'crucifix', is a powerful manifestation of the gravity of the impact of society's judgments on self-image.

Nonetheless, not all the participants were as forthcoming nor connected with their struggles with their body image. In the case of Blue Bunny and Powerpuff Girl, they both exhibited an outward disconnection with their 'selfportraits', which deviated from the 'self-portraits' themselves.

Figure 5. 'Self-Portrait' of Blue Bunny

According to Blue Bunny, she felt "no emotions" while drawing. Moreover, she described her feeling toward her "selfportrait' as "oddly detached". Yet the furious pen strokes of Blue Bunny's 'self-portrait' seems to suggest that she was unleashing all her pent-up emotions within her. It is also noticeable that her strokes are most intense in the stomach, which is a very common area for body weight insecurity and also a site where one often experiences the 'butterflies' of anxiety.

While Blue Bunny may not have been aware of this, her engagement in the process of creating this 'selfportrait' may have helped her to unleash her negative feelings at an unconscious level. This emptying out of her emotions could perhaps explain the absence of emotions within her. 
What is striking about the 'self-portrait' of Powerpuff Girl is the noticeable absence of a face - the quintessence of a person. Her explanation of her 'self-portrait', with a focus on her outfit, makes her come across as a mannequin, rather than a human: "There's no real abstract thing to it, it is just how I see myself in the mirror. That outfit is one of my favorites and I just feel confident in it." As with Blue Bunny, she also asserted that her depiction had "no particular emotion behind it." However, her claim that this faceless image resembled her reflection in the mirror thought of as "me, myself, and I" showed a high degree of estrangement of her body image from her true feelings.

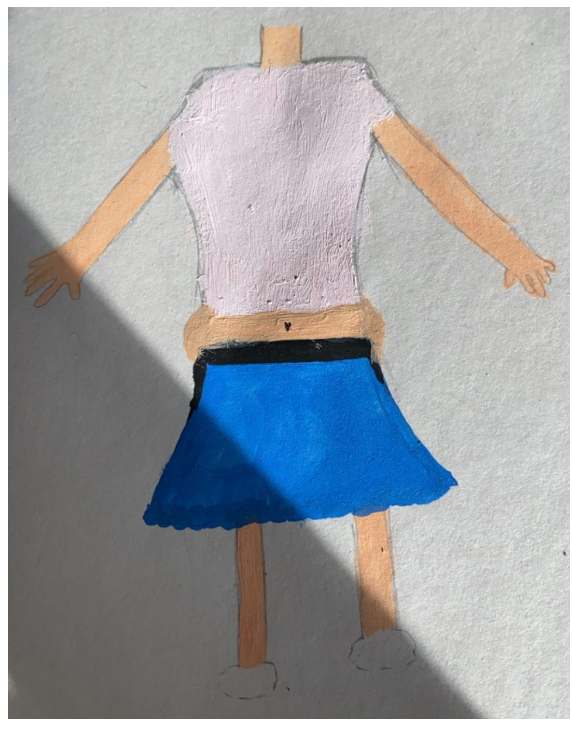

Figure 6. 'Self-Portrait' of Powerpuff Girl

Despite their outwardly calm demeanors, these two participants, to me, epitomize the severity of the impact of body image issues. Their lack of emotions suggests that they had become highly disconnected from their sense of identity. Coping with their body image issues had come at the price of severing their connection with their inner selves. Thus, it is my hope that this workshop could encourage them to face up to their body image issues in an honest way, as in the case of their peers.

\section{Theme 2: Provision of Safe Space for Expression, Connection and Healing}

For the participants who had been struggling with body image issues in isolation, the workshop provided a liberating platform for bringing out their repressed feelings into the open. The creative outlet of making their 'self-portraits' had a highly therapeutic effect on the participants:

It made me feel like I could let out all my emotions and create a piece of art with what's on my mind... Drawing this made me feel expressive. (July)

The process of creating their artwork and the accompanying reflections enabled the participants to see themselves with 'new' eyes, independent of conventional beauty standards. For example, in her 'self-portrait', SpongeBob produced a composite picture of herself, which included not just her body, but also her diverse interests like reading, music and cooking (see Figure 7). Even her description of her physical appearance deviated largely from the parameters of weight and acne: 
This was just an attempt to draw how I think I look: I have almond-shaped eyes, especially when I smile. Some people think I'm Japanese, but I'm not. I have a somewhat projecting lower jaw, which is apparently an Indian thing.

Figure 7. 'Self-Portrait' of SpongeBob

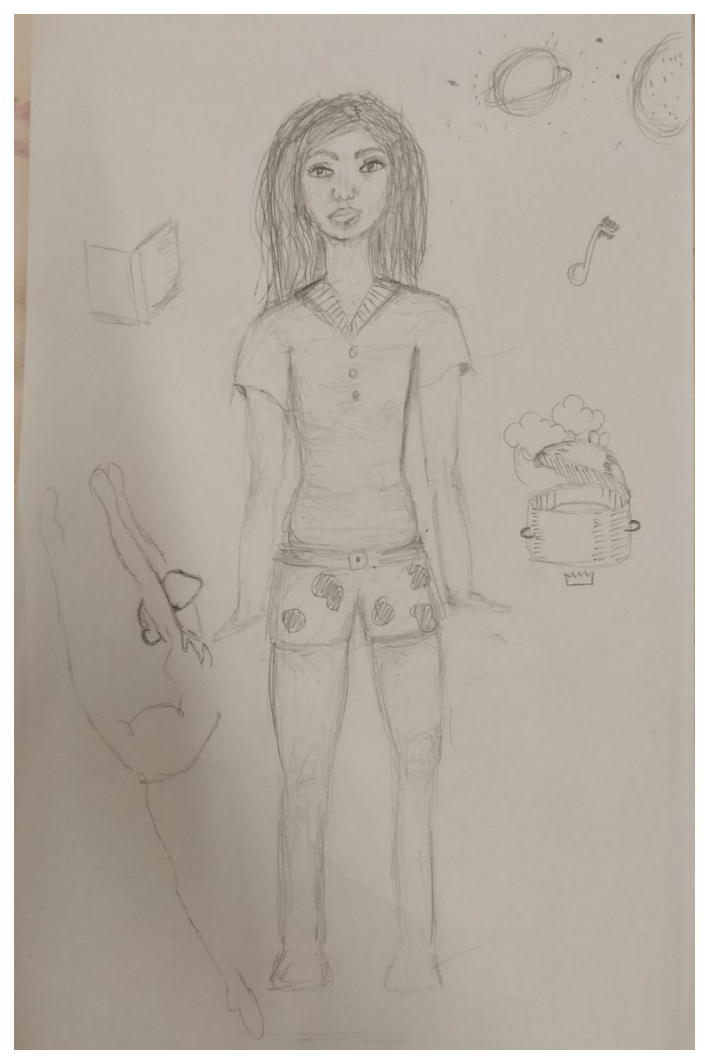

In fact, the process helped SpongeBob to connect with her body image in a more honest and concrete manner:

"Drawing this made me feel more definite than an abstract interpretation, like my features were facts rather than an abstract form of beauty."

Sudoku also experienced the nurturing effects of connecting with herself, away from the judgmental gaze of the society (see Figure 8).

This ultimately allowed her to develop a more positive self-image: 


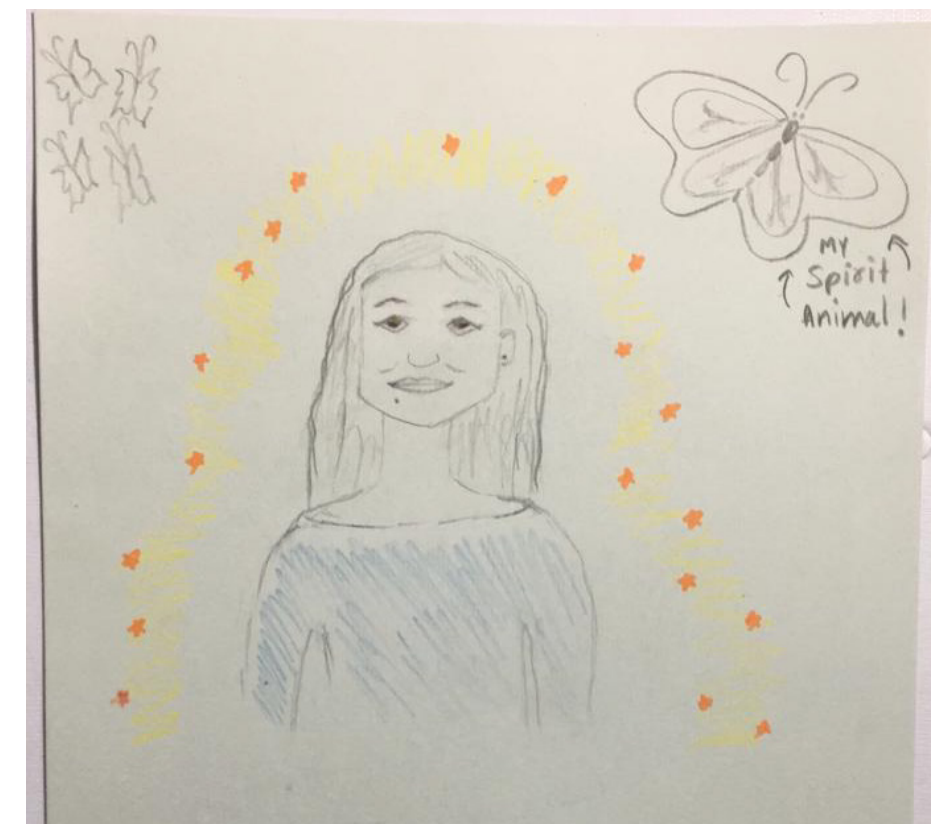

Figure 8. 'Self-Portrait' of Sudoku

"I never take out the time to think about myself, my body, and the way I look. So doing that while knowing that no one would judge me felt very nice... I kind of discovered how I think of myself, because while drawing, I couldn't think of anything negative being a representative of me."

As with SpongeBob's 'self-portrait', Sudoku's version of herself also displays a certain degree of creative deviation from conventional depictions. Her introduction of butterflies — what she called "my spirit animal" — and a 'halo' of stars brought her personality into the picture.

The creative component of this workshop thus provided the participants with a safe space for them to express their struggles with body image issues in a healthy way. Living in the Indian society, where the preponderant emphasis is placed on competitive academic performance and achievements (Rentala et al., 2019), overall emotional well-being often takes second place, which also includes body image issues that are unaddressed.

Being in a space in which they could create their 'self-portraits', share about them, and receive input from their peers offered a precious sense of connection that is in stark contrast to their isolation. Suddenly, they didn't feel so "alone":

It feels good to know that I'm not alone in having negative body image issues... Everyone has things they want to change about themselves. (Pink Panther)

I wasn't alone in how I feel. (Powerpuff Girl)

I can definitely see myself relating to what most people say. (Sudoku)

It made me realize that I'm not the only one. (July)

Although the participants were complete strangers to one another at the start of the session, this brief interaction brought them an overwhelming sense of unity and provided them with a collective healing experience:

Even though we are of different age brackets, we all have this one problem in common... (July)

Now that I've seen that we're all insecure about something or the other, my body is not something that will ever really hinder my confidence because I know how other people feel about theirs. (SpongeBob) 


\section{Theme 3: Transformation through Self-Empowerment and Advocacy}

The participants' body image 'journeys' during this workshop culminated in their recognition of the need for self-love and acceptance. Sudoku's emerging sense of self-love was certainly captured in her gentle representation of herself, with butterflies that she considered to be her incarnation and a shiny halo of stars (see Figure 8):

I guess thinking positively about my body through the 'self-portrait' has gotten me one step closer to taking that perception out of my mind. I guess this is what being happy about your body and yourself feels like.

Whether she was conscious of it or not, Sudoku's choice of depicting herself as a butterfly could symbolize a metamorphosis of sorts- her re-emergence as one who was free from society's standards.

For July who went through a very challenging identity crisis during which her body was under siege from peer judgment (see Figure 3), this difficult phase enabled her to blossom into a young woman who is full of self-love (see Figure 9).

Figure 9. 'Self-Portrait' of July (2)

July's 'self-portrait' of a shapely female form in all its natural splendor amidst lush green foliage and blooming flowers of a diversity of colors and shapes is a beautiful celebration of her embrace of her budding womanhood. In her comments about her drawing, July highlighted her recognition that her passage through the "rocky road" of being judged by others helped her to become the strong and joyful woman she was today:

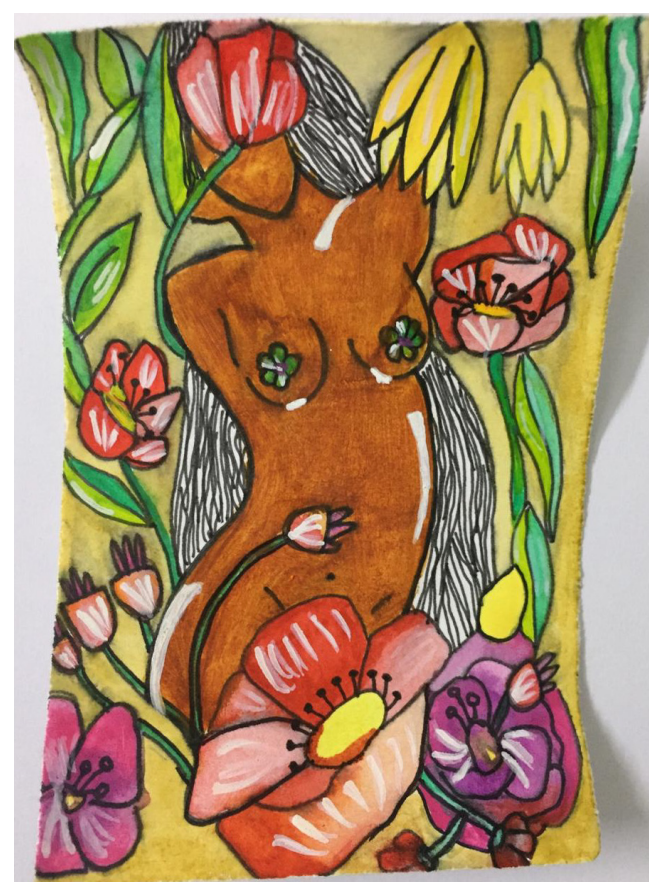

"I drew this because I feel like teenage is a phase where you're just breaking and blooming. Teenage is like a rocky road to your true identity, to becoming a woman. This is our body. You have to love yourself in all forms. This is what we are. At the end of it, we're all going to be really happy with who we are."

"As long as you love your body, I don't think anyone has the right to make fun of you or say anything about it. Even if they do, you just need to laugh it off because it's your body and you have all rights over it. You can do whatever you want as long as it makes you happy." 
The overflow of self-love by almost all participants triggered an inspiring discussion in which their self-empowerment translated naturally into advocacy against the blind adherence to conventional norms of beauty:

As I was trying to draw myself, I realized that I was trying to fit a certain type... I didn't want to draw curves, acne, or body hair since these are traditionally thought of as "ugly" or "flaws" due to media influence. [However, I now realize that] these are all natural and beautiful things and should be treated as such. (Tweety)

Observing that beauty standards were already undergoing renovation - "these beauty standards have already started shedding off people's minds" (July), the participants were excited about their common 'mission' of redefining these norms in their own different ways.

For Powerpuff Girl and Pink Panther, this meant redefining the standards of beauty by emphasizing the uniqueness of each individual's beauty:

I have always felt that words like "beauty standard" are ridiculous. Every single human is beautiful in their own way, whether they realize it now or not. (Powerpuff Girl)

I feel that no standard should decide how I choose to feel about myself. (Pink Panther)

As for Tweety and July, they prided themselves on deliberately transgressing against gender-prescribed clothes by adopting androgynous fashions:

I wear gender-neutral clothes. My whole family thinks that I should dress more "girly". But I don't think anyone should be forced to wear clothes which are allotted to a particular binary gender. (Tweety)

I steal my dad's clothes all the time because if you are confident in carrying that piece of clothing, people are going to admire you for your confidence. (July)

Nonetheless, the participants also recognized that such a change could not be accomplished overnight. July was particularly cognizant of the work that lay ahead for them, while acknowledging that progress has been made:

These norms in society were brought about before we were even here. It is going to take a lot of time and effort to change society and make it comfortable for everyone to live in.

We are more accepting in comparison to how people were back in the day, but it will take a lot of time. This is just the start.

Given the challenge, constant reflection and discourse are vital to consciously overwrite prevalent societal attitudes. The participants all concluded that the key to transforming these norms lay in first in adopting a conscious, openminded, and empathetic outlook:

I feel like how much ever we might talk about it, our subconscious opinions contradict it. So maybe be conscious about it every time you see it and go the extra mile? I'm sure that things will pop up in the future that we aren't accustomed to today and then we'll be in our parents' position. The real task here is mutual empathy and understanding. (SpongeBob)

I want to be a very accepting person, because then maybe the future generations will not be scared to reveal their actual self to us. (July) 


\section{Conclusion}

On the whole, this study has demonstrated the effectiveness of an innovative workshop that involves the creation and sharing of 'self-portraits' in an anonymized online setting on the body image of Indian female teenagers, aged 13 to 16. Specifically, the workshop enabled the participants to openly acknowledge their hyperconsciousness about their body image and the sense of isolation they experienced. Furthermore, they could see clearly how they had internalized the mainstream beauty standards due to external pressures from family, media, and peers. The well-established stigma around body weight, body hair and skin conditions like acne in modern Indian society (Chaturvedi et al., 2005; Gelles, 2011) was highlighted in this study directly through the voices of these participants. It was evident how they had suffered from the pressure to conform to such unrealistic expectations.

There were two participants - Blue Bunny and Powerpuff Girl — whose emotionless descriptions of their 'self-portraits' seemed to suggest that they were unscathed by body image issues. However, their drawings, one with intense strokes and the other resembling a mannequin, suggest otherwise, i.e., their repression of their true feelings about their physical appearance, which they were unable to articulate verbally.

Furthermore, the sessions were also effective in providing the participants with an opportunity to truly express and channel their feelings in a safe environment. This collective sharing experience was transformative for many, as they realized that they were not alone. What they had been enduring on their own was not something that affected them solely. Inspired by one another, the participants could move towards finding self-acceptance.

Feeling liberated from societal norms, these participants also felt inspired to fight to redefine beauty standards at a community level and take pride in their existing habits of dressing against the gender-norms. This was an empowering conclusion to a discussion, which helped the participants to challenge their own internalized stereotypes.

Ultimately, the workshop affirmed the extent to which Indian female teenagers' body image issues accorded with the prevalent literature on the subject. Sadly, the participants confirmed their internalization of the unrealistic body standards as shown by Gelles (2011). The effect of bullying and pressure from peers and media during puberty when the body rapidly changes (Voelker et al., 2015; Webb \& Zimmer-Gembeck, 2013) was also corroborated by the participants' comments, as in the case of July:

I've really been bullied, for whatever reasons, and other people have been bullied too... [I wish we could help] change the bullies and make them realize how badly their actions affect other people.

The severe effects of harsh standards, judgement, criticism and bullying on Indian female teenagers were clearly brought out. Interestingly enough, July recognized that the bullying and insecurities were only temporary and that one could grow past these issues to emerge victorious. This positive outlook has not yet been studied in great detail and could offer further scope for further research. Perhaps, a research study could adopt a longitudinal approach by studying the evolution of Indian teenagers' body image issues over time as they traverse through the different pubertal phases.

More specifically, the act of creating 'self-portraits' helped the participants to truly get in touch with their feelings and express unconscious struggles, which substantiates the usefulness of art therapy as an instrument for healing one's body image (Gaete, 2010). Many of these images were highly creative, expressive, and emotionally advanced, surfacing issues that were erstwhile buried in the unconscious, which were easier manifested in their creative works than in spoken words.

The insights obtained from this study could be useful for conducting similar sessions in the future. This would further help Indian female teenagers with body image issues to break out of the confines of the beauty norms of urban Indian society. Here are some specific recommendations:

1. Conduct weekly one-hour workshops during which Indian teenagers of one or multiple genders could come together to express their feelings about their body image 
2. Expand existing body image workshops to include elements of creative expression such as drawing to enable participants to get in touch with inner feelings.

3. Create parenting blogs and workshops to:

a) expose parents to varied beauty standards and help them to adopt an open-minded and supportive attitude towards their children's physical appearances;

b) provide parents with body positive media like song and movie recommendations, quotes, and videos of people talking about and addressing body image that they can share with their children;

c) encourage parents to open dialogues with their children on these topics to promote sensitivity in their children and deter them from bullying others about physical appearances.

4. Support innovative initiatives like cross-dressing parties to celebrate clothing that may not conform to the existing gender norms.

Given the small sizes of the two groups taking part in the sessions, the impact of the workshop was all the more remarkable. All the participants expressed a desire to participate in more such workshops, and have them conducted not only for girls, but also boys. Thus, this workshop could constitute a vital beginning of an empowering mission for Indian teenagers to overturn generations-old beauty standards and liberate their peers from the prison of the 'slim ideal'.

\section{References}

Chaturvedi, S. K., Singh, G., \& Gupta, N. (2005). Stigma experience in skin disorders: An Indian perspective. Dermatologic Clinics, 23(4), 635-642. https://www.researchgate.net/publication/7649159 Stigma Experience in Skin Disorders An Indian Perspective

Gaete, M. I. (2010). Working with the body image through the art-therapy technique. Proceeding of the Rio International Eating Disorders and Obesity Conference, Rio de Janeiro, Brazil. Research Gate. https://www.researchgate.net/publication/274380909

Gelles, R. (2011). Fair and lovely: Standards of beauty, globalization, and the modern Indian woman [Unpublished Manuscript]. Independent Study Project (ISP) Collection 1145. https://digitalcollections.sit.edu/isp collection/1145

Pietkiewicz, I., \& Smith, J. A. (2014). A practical guide to using Interpretative Phenomenological Analysis in qualitative research psychology, Czasopismo Psychologiczne - Psychological Journal, 20(1), 7-14. https://www.researchgate.net/publication/263767248 A practical guide to using Interpretative Phenomenological Analy$\underline{\text { sis in qualitative research psychology }}$

Rentala, S., Nayak, R. B., Patil, S. D., Hegde, G. S., \& Aladakatti, R. (2019). Academic stress among Indian adolescent girls. Journal of Education and Health Promotion, 8(1), 158. https://pubmed.ncbi.nlm.nih.gov/31544123/

Sanders, J. (2013). The use of art in therapy: An exploratory study. Sophia, the St. Catherine University Repository. https://sophia.stkate.edu/msw papers/257

Smith, J.A. \& Osborn, M. (2008). Interpretative phenomenological analysis. In J.A. Smith (Ed.) Qualitative Psychology: A practical guide to research methods (pp. 53-80). Sage. 
Voelker D.K., Reel J.J., \& Greenleaf C. (2015) Weight status and body image perceptions in adolescents: current perspectives, Adolescent Health, Medicine and Therapeutics, 6, 149-158. https://doi.org/10.2147/AHMT.S68344

Webb, H. J., \& Zimmer-Gembeck, M. J. (2013). The role of friends and peers in adolescent body dissatisfaction: A review and critique of 15 years of research. Journal of Research on Adolescence, 24(4), 564-590.

https://doi.org/10.1111/jora.12084 